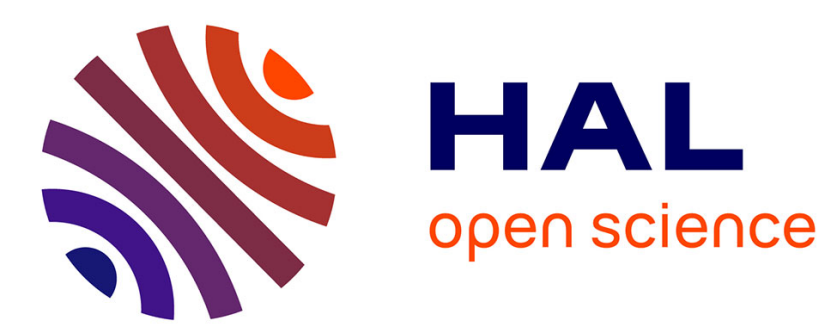

\title{
Effect of Aluminum Reinforcement on the Dynamic Fragmentation of SiC Ceramics
}

Pascal Forquin, Lisa Tran, Pierre-François Louvigné, Laurent Rota, François Hild

\section{- To cite this version:}

Pascal Forquin, Lisa Tran, Pierre-François Louvigné, Laurent Rota, François Hild. Effect of Aluminum Reinforcement on the Dynamic Fragmentation of $\mathrm{SiC}$ Ceramics. International Journal of Impact Engineering, 2003, 28, pp.1061-1076. 10.1016/S0734-743X(03)00034-4 . hal-00002909

\section{HAL Id: hal-00002909 https://hal.science/hal-00002909}

Submitted on 20 Sep 2004

HAL is a multi-disciplinary open access archive for the deposit and dissemination of scientific research documents, whether they are published or not. The documents may come from teaching and research institutions in France or abroad, or from public or private research centers.
L'archive ouverte pluridisciplinaire HAL, est destinée au dépôt et à la diffusion de documents scientifiques de niveau recherche, publiés ou non, émanant des établissements d'enseignement et de recherche français ou étrangers, des laboratoires publics ou privés. 


\title{
Effect of Aluminum Reinforcement on the Dynamic Fragmentation of SiC Ceramics
}

\author{
Pascal Forquin, ${ }^{\mathrm{a}, \mathrm{b}, 1}$ Lisa Tran, ${ }^{\mathrm{a}}$ \\ Pierre-François Louvigné, ${ }^{\mathrm{a}}$ Laurent RotA ${ }^{\mathrm{a}}$ and \\ François HILD ${ }^{b}$ \\ ${ }^{a}$ DGA/CTA-Département MSP \\ 16 bis avenue Prieur de la Côte d'Or, F-94114 Arcueil Cedex, France. \\ ${ }^{\mathrm{b}} L M T-C a c h a n$ \\ ENS de Cachan / CNRS-UMR 8535 / Université Paris 6 \\ 61 avenue du Président Wilson, F-94235 Cachan Cedex, France.
}

$\overline{1}$ to whom correspondence should be addressed. Fax: $+33 \quad 1 \quad 42 \quad 319847$ Email: pforquin@etca.fr. 


\title{
Effect of Aluminum Reinforcement on the Dynamic Fragmentation of SiC Ceramics
}

by

\author{
P. Forquin, L. Tran, P.-F. Louvigné, L. Rota and F. Hild
}

\begin{abstract}
The threat of small to medium calibre armor piercing projectiles requires efficient protections that can be achieved by using bilayered configurations. They consist in a front face made of a hard material and a backing made of a ductile material. These solutions are among the most interesting in terms of mass efficiency. To design such bilayered concepts, one needs to understand and model fragmentation of the ceramic during the first microseconds after impact. This cracking pattern may significantly reduce the multi-hit capability of the armor. A new material made of porous silicon carbide infiltrated with aluminium is considered. The presence of an aluminum skeleton may improve the residual strength after impact. The present study deals a comparison of fragmentation properties of this new material with those of porous silicon carbide. Quasi-static experiments and edge-on-impact tests are performed. The role of aluminum is discussed. An anisotropic damage model coupled with a fragmentation study is used to analyze the experimental observations.
\end{abstract}

Keywords: SiC ceramics/ squeeze casting/ Continuum Damage Mechanics/ dynamic fracture/ Weibull model 


\section{Introduction}

Bilayered armors using hard materials such as ceramics (e.g., alumina, silicon carbide, quartz) as front plate and ductile materials (e.g., steel, aluminum alloy, composite or polycarbonate) as backing face have been studied for several years to improve the efficiency of light or medium armors [1]. The high hardness of ceramic materials favors projectile blunting and/or failure and spreads the kinetic energy on a large surface of the ductile backing. The weight of the armor is then reduced in comparison to an armor made of steel only. This combination is especially appealing when dealing with small to medium armor piercing calibers (e.g., AP $7.62 \mathrm{~mm}$ or AP $12.7 \mathrm{~mm}$ ). Figure 1 shows a comparison of different configurations in terms of limit velocity of penetration as a function of mass per unit surface of armor. An AP $12.7 \mathrm{~mm}$ projectile was used. It can be concluded that the efficiency of monolithic armors is virtually independent of the material shown in Fig. 1. However, when a silicon carbide ceramic is combined with a $50 \mathrm{~mm}$ thick honeycomb aluminum, it leads to better results when compared to different monolithic materials [2] for which the impact velocity is greater than $500 \mathrm{~m} / \mathrm{s}$. Similar trends have been reported with an alumina ceramic combined with an aluminum backing [1].

Furthermore, Riou [3] performed experiments on bilayered configurations with different thicknesses of the ceramic layer. A significant degradation of the ceramic was observed in a normal impact test (Fig. 2-a). The fragmentation is caused by tensile hoop stresses and strains induced by the radial motion of the ceramic after impact. To visualize fragmentation, a so-called edge-on-impact (EOI) configuration can be used. These configurations were developed by the Ernst-Mach-Institut (EMI) in Germany [4-6] and more recently by the Centre 
Technique d'Arcueil (CTA) in France [3,7]. The same damage mechanism (i.e., multiple cracking) is observed in EOI for bilayered and monolithic ceramics (Fig. 2-b) and in normal impact configurations (Fig. 2-a). This result can also be obtained numerically [8]. To allow for post-mortem observations, a sarcophagus configuration was designed [9] (Fig. 2-c). These studies enabled for a comparison between different ceramics in terms of fragmentation features [10]. To limit the perforation of the ceramic, a material leading to a small crack density was recommended. Yet, the multi-hit strength is still low with these material combinations.

Another route can be followed to improve the multi-hit capability of a bilayered armor. It consists in avoiding or reducing the motion of the fragments. To achieve this property, a porous $\mathrm{SiC}$ ceramic is infiltrated by aluminum $[11,12]$. Aluminum induces a better cohesion to the impacted material thereby increasing the residual strength after impact. To illustrate this feature, Fig. 3 shows a block of armor made of 3 tiles of infiltrated ceramic encased in a $15 \mathrm{~mm}$ thick aluminum layer that was impacted by an AP 7.62 P80 projectile travelling at $847 \mathrm{~m} / \mathrm{s}$. One can note no penetration even though a very dense cracking occurred in the first layer (see micrographs of Fig. 3).

To design bilayered armors, one has to model damage caused by impact in the brittle material. To achieve this goal, a comparison of the fragmentation features of the infiltrated ceramic with those of the porous $\mathrm{SiC}$ material is performed. Section 2 introduces the two materials studied herein. Mechanical and failure properties are obtained under quasi-static loading conditions. EOI experiments are then discussed in Section 3. Three different sets of data are obtained. Based upon a fragmentation theory, a so-called local damage model [10] is summarized in Section 4. This model is used to analyze the different 
fragmentation conditions observed in the previous section.

\section{Studied Materials}

The armor concept consists in a compact aluminum box of size $160 \times 90 \times$ $45 \mathrm{~mm}^{3}$ [13]. The box contains one or several ceramic tiles (e.g., three in the present case) surrounded by a steel casing on the first half of its thickness, located close to the impacted surface (Fig. 3). The steel casing has two functions: first, to maintain the ceramic tiles in position during squeeze casting, and second, to constrain the ceramic during impact. The R-SiC tiles, which are obtained by sintering of $\mathrm{SiC}$ powder by Saint-Gobain industrial ceramics (commercial name: Crystar $\left.{ }^{\circledR}\right)$, are porous (Fig. 3). The open porosity of the $\mathrm{R}-\mathrm{SiC}$ tiles is regular and continuous from one side to the other one, in a such way that aluminum will fill most of the open cavities during the squeezecasting process. An initial porosity of the order of $17 \%$ was measured [14]. The second half of the thickness of the box is pure aluminum. The density of the box is close to 2.8, depending on the number of R-SiC tiles used.

Before infiltration, the ceramic tiles are encased in a steel canister perforated by numerous holes to allow for the penetration of liquid aluminum. The cannister is heated up in a furnace to allow for a complete filling of the pores during infiltration and a bond of the tiles with the encasing. After preheating, it is put in a die of a UBE HVSC 350 indirect squeeze casting equipment (at ARC Leichtmetallkompetenzzentrum Ranshofen (LKR), Austria) and infiltrated with liquid aluminum or an aluminum-silicon alloy by applying a pressure of about $70 \mathrm{MPa}$. The armor presented herein has also been manufactured at LKR where the technology has been developed in cooperation 
with CTA. Image analyses of micrographs of the $\mathrm{R}-\mathrm{SiC}-\mathrm{Al}$ material are used to determine the volume fraction of aluminum (i.e., 14.5\%) and the remaining porosity (i.e., 2.5\%) [14].

The elastic properties of the two materials are obtained by using ultrasound experiments. The velocities of longitudinal and transverse waves are measured and the elastic properties of an isotropic and elastic material can be deduced [15]. Table 1 summarizes the results obtained for the two ceramics. A comparison is given with a steel to be used in the EOI experiments. The presence of aluminum increases the Young's modulus of the material as well as the density when compared to the raw R-SiC ceramic. However, these values are still less than those obtained for other SiC grades (e.g., SiC-100 and SiC-B, see Table 1).

To evaluate the fracture properties under quasi-static loading condition, 3point flexure experiments are carried out. The failure load is scattered so that a Weibull model $[16,17]$ is used. The failure probability $P_{\mathrm{F}}$ is expressed as

$$
P_{\mathrm{F}}=1-\exp \left[-V_{\text {eff }} \lambda_{0}\left(\frac{\left\langle\sigma_{\mathrm{F}}\right\rangle}{\sigma_{0}}\right)^{m}\right]
$$

where $V_{\text {eff }}$ denotes the effective volume [18]

$$
V_{\text {eff }}=\int_{\Omega}\left[\frac{\sigma^{\star}(\boldsymbol{x})}{\sigma_{\mathrm{F}}}\right]^{m} \mathrm{~d} \boldsymbol{x} \text { with } \sigma_{\mathrm{F}}=\max _{\Omega} \sigma^{\star}(\boldsymbol{x}),
$$

corresponding to an equivalent stress $\sigma^{\star}$ (e.g., maximum principal stress) at a given point $\boldsymbol{x}$. The parameter $m$ is the Weibull modulus (i.e., it measures the scatter, the lower $m$, the higher the scatter), $\sigma_{0}$ the scale parameter relative to a reference density $\lambda_{0}$, and $\langle\star\rangle$ the Macauley brackets (i.e., the positive part of $\star)$. The constant $\sigma_{0}^{m} / \lambda_{0}$ is the Weibull scale parameter. By using a beam 
theory, the effective volume can be calculated in 3-point flexure

$$
V_{\mathrm{eff}}=\frac{V}{2(m+1)^{2}}
$$

where $V$ is the loaded volume (i.e., $V=20 \times 3 \times 3 \mathrm{~mm}^{3}$ ). The surfaces in tension were polished prior to the experiments and two chamfers were ground. 19 experiments are performed for the raw R-SiC ceramic and 12 for the infiltrated R-SiC. A stroke rate of $0.1 \mathrm{~mm} / \mathrm{min}$ was applied. Table 1 shows that the Weibull moduli are similar for the two materials. Consequently, it is expected that the defect population is identical in both cases. For the Weibull model, the average failure stress $\sigma_{\mathrm{w}}$ is given by

$$
\sigma_{\mathrm{w}}=\frac{\sigma_{0}}{\left(V_{\mathrm{eff}} \lambda_{0}\right)^{\frac{1}{m}}} \Gamma\left(1+\frac{1}{m}\right)
$$

where $\Gamma$ is the Euler function of the second kind. It can be noted that a significant increase is observed when the two materials are compared. The effect of aluminum infiltration is clearly evidenced by these results. A strong bond can be expected between the R-SiC skeleton and aluminum in EOI experiments.

In Table 1 are also given the properties of two other $\mathrm{SiC}$ ceramics. The raw R-SiC studied herein has failure properties that are significantly lower when compared to SiC-100 (made by Céramique \& Composites, France) or SiC-B (made by CERCOM, USA). The $\mathrm{SiC}-100$ grade is naturally sintered (sintering temperature: $2000^{\circ} \mathrm{C}$ ). The material is not fully dense. No secondary phase can be observed but $\mathrm{B}_{4} \mathrm{C}$ inclusions are present [3] because boron was added to enhance diffusion during sintering. SiC-B ceramics are obtained by pressure assisted densification. Aluminum is used to eliminate porosities (processing temperature: $2000^{\circ} \mathrm{C}$, pressure: $15 \mathrm{MPa}$ ). An alumina-rich secondary (glassy) phase is present [19]. It can also be noticed that the Weibull moduli of three 
$\mathrm{SiC}$ grades are of the same (high) order of magnitude.

\section{Edge-On-Impact Experiments}

The dynamic fragmentation is studied by using EOI configurations. It consists in impacting a ceramic (or a glass) on the edge so that a ultra-high speed camera can be used to visualize the kinetics of the fragmentation process or microscopic analyses can be carried out to observe the post-mortem cracking pattern. The interframe time can be as low as $0.2 \mu \mathrm{s}$. A projectile made of high strength steel (AFNOR designation: 35NCD16) is fired by a gas launcher with velocities ranging from 100 to $450 \mathrm{~m} / \mathrm{s}$ for a steel projectile (length: $15 \mathrm{~mm}$, diameter: $11 \mathrm{~mm}$ ). Figure 4 shows a schematic of the experimental set-up. The sample is put in an aluminum container. The projectile speed is measured by two optical cells $50 \mathrm{~mm}$ apart. When the bullet reaches the second cell, the flashlight is triggered, and when it impacts the target, it activates the camera to take pictures. To get a good contrast, a very thin aluminum layer is deposited on the surface of interest. The observation axis is symmetric with respect to the mean illumination direction. The size of the tested tiles is $60 \times 30 \times 8 \mathrm{~mm}^{3}$.

Figure 5 shows two series of pictures obtained for the two ceramics when impacted at $200 \mathrm{~m} / \mathrm{s}$. For the raw ceramic (Fig. 5-a), one can see a very intense damage front invading the tile $(t=3 \mu \mathrm{s})$ followed by a coarser pattern as time increases. The same observations can be made for the infiltrated ceramic (Fig. 5-b). The latter results show a vertical line appearing around $t=4 \mu \mathrm{s}$. This line was already visible prior to the experiment. It corresponds to a crack running across the whole ceramic that was filled with aluminum. It 
was probably caused during the infiltration stage since the applied pressure is of the order of $70 \mathrm{MPa}$. This first series of experiments does not allow us to differentiate the fragmentation features of the two materials. However, after the experiment it was noted that R-SiC ceramics were fully fragmented whereas the R-SiC-Al tile had intact parts. A second EOI configuration is used to analyze dynamic fragmentation.

A so-called sarcophagus configuration is used (see Fig. 2-b). Instead of utilizing a high speed camera, the present configuration enables us to maintain the fragments in place. The impendence of the confinement needs to be less than that of the ceramic so that the "confinement" does not interfere with the impacted ceramic. After impact, the tile is infiltrated by a hyper-fluid resin and polished for macroscopic and microscopic analyses. Three different experiments are reported. Two impact velocities (namely, 100 and $200 \mathrm{~m} / \mathrm{s}$ ) are used for the R-SiC ceramic. Only one velocity is reported for the infiltrated ceramic (i.e., $200 \mathrm{~m} / \mathrm{s}$ ) since the average strength of infiltrated R-SiC is about twice that of the raw ceramic (Table 1). For a velocity of $100 \mathrm{~m} / \mathrm{s}$ on an infiltrated ceramic, no fragmentation was observed and only few macrocracks are observed. The same sample geometry as before is used here.

The macroscopic and microscopic post-mortem cracking pattern is shown in Fig. 6. Different zones can be separated with respect to the crack density. The top views of Fig. 6 show that in front of the projectile, a first zone experiences a very fine cracking pattern. In a second zone, one can observe long radial cracks. For the raw $\mathrm{SiC}$ impacted at $100 \mathrm{~m} / \mathrm{s}$, the first zone has a size of the order of $17 \times 11 \mathrm{~mm}^{2}$. This zone has a size of $20 \times 25 \mathrm{~mm}^{2}$ when the impact velocity is equal to $200 \mathrm{~m} / \mathrm{s}$. For the infiltrated ceramic impacted at $200 \mathrm{~m} / \mathrm{s}$, the size of the first zone is significantly reduced (i.e., 
$\left.15 \times 15 \mathrm{~mm}^{2}\right)$. Furthermore, the erosion of the raw $\mathrm{SiC}$ is more important compared with the infiltrated ceramic. The bottom views of Fig. 6 show that in the first zone the cracking pattern is mainly oriented along the radial direction. These micrographs correspond to the same location (i.e., $13 \mathrm{~mm}$ ahead of the impact center). When the two tests are compared for raw $\mathrm{SiC}$, one can note an increase of the cracking density with the impact velocity. When the same velocity is considered, smaller cracks can be seen in the infiltrated material. This trend was also observed for another $\mathrm{SiC}-\mathrm{Al}$ material [12] for which it was concluded that only a limited number of cracks was generated when compared to dense SiC-100 and hipped SiC. All these observations are now analyzed with a damage model based upon a fragmentation analysis.

\section{Numerical Analysis of the Fragmentation in $\mathrm{SiC}$ Ceramics}

The fragmentation process is discrete by essence. In the theory developed by Mott [20], the fragmentation of a rapidly expanding ring was studied. Even though it is based on some heuristics, its contains some key ingredients (i.e., the randomness of the process is clearly stated and accounted for) to analyze the distribution of fragments in 2D experiments [21]. From a numerical point of view, discrete modelings are also proposed [22-24] when the fragment size is greater than or equal to the size of a representative element. Espinosa et al. [25] have developed a continuum/discrete multi-scale model in which the finer scale is discrete and allows for the derivation of a continuum description on a higher scale. Alternatively, Continuum Damage Mechanics can be used with an isotropic [26-28] or anisotropic [29] damage description to account for multiple fragmentation. Consequently, in the numerical simulations, the medium is assumed to be continuum on the scale of a finite element in which 
numerous cracks are expected to form. In the following, a damage model based upon a fragmentation analysis is used.

\subsection{Damage Model}

For brittle materials, the analysis of failure depends upon the microstructure in terms of flaw density and failure stress distribution [30]. In the present analysis, it is assumed that cracking occurs normal to three directions $\boldsymbol{d}_{i}(i=1,2,3)$. The microstructure is approximated by point defects of density $\lambda_{\mathrm{t}}$ with random locations. It can be described by a Poisson point process of intensity $\lambda_{t}[31,32]$

$$
\lambda_{\mathrm{t}}\left(\sigma_{i}\right)=\lambda_{0}\left(\frac{\left\langle\sigma_{i}\right\rangle}{\sigma_{0}}\right)^{m}
$$

Equation (5) shows that the higher the local principal stress $\sigma_{i}$, the more defects can break. Under impact, a whole cracking pattern is observed as shown in Section 3. In the following, it is assumed that the defect population leading to damage and failure is identical when the material is subjected to quasi-static and dynamic loading conditions [30,33]. To understand why a crack nucleates, one has to model the interaction of a nucleated defect and other defects that would nucleate. The crack propagation velocity is assumed to be constant and equal to a fraction $k$ of the longitudinal wave speed $C_{0}$ $[34,26,7]$. Therefore, one may define a relaxation or obscuration domain of volume $V_{\mathrm{o}}$ around a crack of normal $\boldsymbol{d}_{i}$ (i.e., a zone in which the stresses are less than the applied stresses, thus do not cause new crack initiations)

$$
V_{\mathrm{o}}=S\left[k C_{0}(t-\tau)\right]^{3},
$$

which is a function of a shape parameter $S$, the present time $t$ and the time to nucleation $\tau<t$. The shape parameter $S$ may depend on the Poisson's ratio 
$\nu$ but it is independent of time so that the relaxed zones are self-similar. New cracks will initiate only if the defect exists in the considered zone and if the flaw does not belong to any relaxed zone. It can be noted that the relaxation volumes are associated with a cracking normal $\boldsymbol{d}_{i}$. The total flaw density $\lambda_{\mathrm{t}}$ can be split into two parts: namely, $\lambda_{\mathrm{b}}$, the cracking density and the obscured flaw density. The increment of the cracking density $\lambda_{\mathrm{b}}$ can be related to that of total flaw density $\lambda_{\mathrm{t}}$ by [35]

$$
\frac{\mathrm{d} \lambda_{\mathrm{b}}}{\mathrm{d} t}=\frac{\mathrm{d} \lambda_{\mathrm{t}}}{\mathrm{d} t} \times\left(1-P_{\mathrm{o}}\right)
$$

with $\lambda_{\mathrm{b}}(0)=\lambda_{\mathrm{t}}(0)=0$ and $P_{\mathrm{o}}$ the probability of obscuration associated to the cracking normal $\boldsymbol{d}_{i}$

$$
P_{\mathrm{o}}=1-\exp \left[-\widehat{V}_{\mathrm{o}}(t) \lambda_{\mathrm{t}}\left\{\sigma_{i}(t)\right\}\right]
$$

where $\widehat{V}_{\mathrm{o}}$ is the volume of the mean obscuration zone

$$
\widehat{V}_{\mathrm{o}}(t) \lambda_{\mathrm{t}}\left\{\sigma_{i}(t)\right\}=\int_{0}^{t} V_{\mathrm{o}}(t-\tau) \frac{\mathrm{d} \lambda_{\mathrm{t}}}{\mathrm{d} \tau}\left\{\sigma_{i}(\tau)\right\} \mathrm{d} \tau
$$

It can be noted that Eqn. (8) accounts for overlappings of obscuration zones. Based upon the fragmentation analysis, a damage model is now developed. The variable $P_{\mathrm{o}}$ can be used to define a damage variable in the framework of Continuum Damage Mechanics [35]. The probability $P_{\mathrm{o}}$ is assumed to be equal to the damage variable $D_{i}$ associated to the direction $\boldsymbol{d}_{i}$. It is interesting to mention that the first order approximation of Eqn. (8) leads to the differential equation proposed by Grady and Kipp [26] to describe the kinetics of an isotropic damage variable. In the present analysis, an anisotropic description is used. The kinetics of each damage variable $D_{i}$ is based upon the defect density $\lambda_{\mathrm{t}}$ and is derived by using Eqn. (8)

$$
\frac{\mathrm{d}^{2}}{\mathrm{~d} t^{2}}\left(\frac{1}{1-D_{i}} \frac{\mathrm{d} D_{i}}{\mathrm{~d} t}\right)=6 S\left(k C_{0}\right)^{3} \lambda_{\mathrm{t}}\left[\sigma_{i}(t)\right] \text { when } \frac{\mathrm{d} \sigma_{i}}{\mathrm{~d} t}>0 \text { and } \sigma_{i}>0
$$


where no index summation is used. The cracking velocity $k C_{0}$ is about 20$40 \%$ the longitudinal wave velocity $C_{0}$ (i.e., $k$ is ranging between 0.2 and 0.4 ), and $S$ is a dimensionless shape factor: in $3 \mathrm{D}$ situations $S \approx 3.74$ [10]. The compliance tensor $\mathcal{K}^{-1}$ is dependent upon the three damage variables $D_{1}, D_{2}$ and $D_{3}$ associated with three perpendicular cracking normals $\boldsymbol{d}_{i}$

$$
\mathcal{K}^{-1}\left(D_{1}, D_{2}, D_{3}\right)=\frac{1}{E}\left[\begin{array}{ccc}
\frac{1}{1-D_{1}} & -\nu & -\nu \\
-\nu & \frac{1}{1-D_{2}} & -\nu \\
-\nu & -\nu & \frac{1}{1-D_{3}}
\end{array}\right]_{\left(\boldsymbol{d}_{1}, \boldsymbol{d}_{2}, \boldsymbol{d}_{3}\right)}
$$

where $E$ is the Young's modulus of the virgin material and $\nu$ the Poisson's ratio. It can be noted that the microscopic and macroscopic stresses are related by the classical effective stress concept [36] associated to each cracking direction

$$
\sigma_{i}=\frac{\Sigma_{i}}{1-D_{i}}
$$

so that the macroscopic strain tensor $\boldsymbol{E}$ is related to the macroscopic stress tensor $\Sigma$ by

$$
\boldsymbol{E}=\mathcal{K}^{-1}\left(D_{1}, D_{2}, D_{3}\right): \boldsymbol{\Sigma}
$$

where ':' denotes the product contracted with respect to two indices. Once the elastic properties and the Weibull parameters are known, the constant $k$ is chosen equal to 0.38 as for other $\mathrm{SiC}$ ceramics $[7,10]$, the model has no other parameters to tune. The following numerical simulations are therefore predictions. 


\subsection{Fragmentation analysis}

Let us now consider a case with a constant stress rate $\mathrm{d} \sigma_{i} / \mathrm{d} t=\dot{\sigma}$. One can define a dimensionless flaw density $\left(\bar{\lambda}=\lambda / \lambda_{\mathrm{c}}\right)$, time $\left(\bar{t}=t / t_{\mathrm{c}}\right)$, volume $(\bar{V}=$ $\left.V / V_{\mathrm{c}}\right)$ and stress $\left(\bar{\sigma}=\sigma / \sigma_{\mathrm{c}}\right)$ from the condition

$$
\lambda_{\mathrm{c}} V_{\mathrm{c}}=1 \text { with } \lambda_{\mathrm{c}}=\lambda_{\mathrm{t}}\left[\sigma\left(t_{\mathrm{c}}\right)\right] \text { and } V_{\mathrm{c}}=V_{\mathrm{o}}\left(t_{\mathrm{c}}\right)
$$

where the subscript ' $c$ ' denotes characteristic quantities. A characteristic stress is defined by $\sigma_{\mathrm{c}}=\dot{\sigma} t_{\mathrm{c}}$. Equation (14) expresses the fact that the characteristic volume $V_{\mathrm{c}}$ contains on average one flaw that may break at the characteristic time $t_{\mathrm{c}}$. By using Eqns. (5) and (14), the characteristic parameters are given by

$$
\begin{gathered}
t_{\mathrm{c}}=\left[\frac{\sigma_{0}^{m}}{\lambda_{0} S\left(k C_{0}\right)^{3} \dot{\circ}^{m}}\right]^{\frac{1}{m+3}}, V_{\mathrm{c}}=\left[\frac{\left(\sigma_{0} k C_{0}\right)^{m} S^{m / 3}}{\lambda_{0} \dot{\sigma}^{m}}\right]^{\frac{3}{m+3}}, \\
\sigma_{\mathrm{c}}=\left[\frac{\sigma_{0}^{m} \dot{\sigma}^{3}}{\lambda_{0} S\left(k C_{0}\right)^{3}}\right]^{\frac{1}{m+3}},
\end{gathered}
$$

and a closed-form solution can be derived for Eqn. (7)

$$
\bar{\lambda}_{\mathrm{b}}(\bar{t})=\frac{m}{m+n}\left[\frac{(m+3) !}{6 m !}\right]^{\frac{m}{m+3}} \gamma\left[\frac{m}{m+3}, \frac{6 m !}{(m+3) !} \bar{t}^{m+3}\right]
$$

where $\gamma$ is the incomplete gamma function. Equation (16) is the exact solution to Mott's problem extended to 3D cases with an initial flaw density modeled by a power law function. When the time $\bar{t}<1$, virtually no obscuration is observed, i.e., $P_{\mathrm{o}} \approx 0$ and $\bar{\lambda}_{\mathrm{b}} \approx \bar{\lambda}_{\mathrm{t}}$. Conversely, when $\bar{t} \gg 1, P_{\mathrm{o}} \approx 1$ and saturation occurs. The higher the Weibull modulus $m$, the higher the density at saturation. By using Eqn. (10), the change of the damage parameter is 
written as

$$
D_{i}=1-\exp \left[-\frac{6 m !}{(m+3) !}{\overline{\sigma_{i}}}^{m+3}\right] \text {. }
$$

Equation (17) shows that $D_{i}\left(\overline{\sigma_{i}}=1\right) \cong 0$ and $D_{i}\left(\overline{\sigma_{i}}=2\right) \cong 1$ (i.e., most of the damage change occurs during a time interval equal to $\left.t_{\mathrm{c}}\right)$. During $t_{\mathrm{c}}$, the horizon is limited by $V_{\mathrm{o}}\left(t_{\mathrm{c}}\right)=V_{\mathrm{c}}$. By using Eqn. (12), the ultimate tensile strength $\left(\mathrm{d} \Sigma_{i} / \mathrm{d} \sigma_{i}=0\right)$, denoted by $\Sigma_{\max }$, is expressed as

$$
\frac{\Sigma_{\max }}{\sigma_{\mathrm{c}}}=\left[\frac{1}{\mathrm{e}} \frac{(m+2) !}{6 m !}\right]^{\frac{1}{m+3}} .
$$

Equations (4) and (18) define two different regimes. The first one is obtained when a weakest link hypothesis is made. It corresponds to single fragmentation. The second one assumes multiple fragmentation. The transition between the 'quasi-static' and 'dynamic' strength can be estimated by the intersection between the weakest link and the multiple fragmentation solutions

$$
\sigma_{\mathrm{w}}=\Sigma_{\max }(\dot{\sigma})
$$

The transition defined by Eqn. (19) allows for the determination of a transition strain rate $\dot{\epsilon}_{t}$ below which single fragmentation occurs and the ultimate strength is strain rate insensitive. Conversely, above the latter, multiple fragmentation occurs and the ultimate strength is strain rate sensitive. For a porous R-SiC ceramic, $\dot{\epsilon}_{t}=530 \mathrm{~s}^{-1}$, whereas for an infiltrated R-SiC, $\dot{\epsilon}_{t}=950 \mathrm{~s}^{-1}$. Because the Weibull moduli of the two materials are of the same order of magnitude, the ratio of the two transition strain rates is close to that of the average failure strengths under quasi-static loading conditions. 


\subsection{Finite Element Computations}

Finite element simulations are performed with the commercial code Pamshock [37] in which the fragmentation and damage models are implemented. For each step, the macroscopic strain increment is given so that the local or microscopic stresses can be computed (since these stresses are elastic). From this information, the damage kinetics is obtained (Eqn. (10)) as well as the cracking density increments (Eqn. (7)) and the macroscopic stresses, which are needed by the code. At the end of each step, the user has access to the damage variables along the three cracking normals, the macroscopic strains, stresses and the densities of cracking. Depending on the problem, any of these quantities can be visualized. In the present case, we will focus on the cracking density along the maximum principal stress direction.

The mesh is shown in Fig. 7 and uses 8-node elements with reduced integration (i.e., only one integration point per element). The two symmetry conditions lead to a mesh made of 5200 elements. The material parameters used in the simulations are given in Table 1 for the tile and the projectile. It should be remembered that no parameter is tuned by using the EOI experiments. Figure 8 shows maps of cracking densities for three different times and three different cases used in the EOI experiments. The dashed boxes correspond to those found experimentally (Fig. 6). When $t=3 \mu \mathrm{s}$, the cracking density is greater than $10^{2.5}$ cracks per millimeter cube in the rectangles. Figures $8-b, c$ show that a damage front gradually invades about one half to two thirds of the tile in less than $4 \mu \mathrm{s}$. The pictures obtained with the high speed camera show a very dense damage pattern created between $3 \mu \mathrm{s}$ and $4 \mu \mathrm{s}$, then followed by long cracks visible after $6 \mu \mathrm{s}$. The simulation is able to find the development 
of the first damage front. However, there is a time lag of about $2 \mu \mathrm{s}$ for the second phase of the cracking pattern. One may argue that the cracks and their openings are too small to be observed by the high speed camera at their inception. It can be noted that after $t=4 \mu \mathrm{s}$, the density in the rectangles does not change significantly. It can therefore be compared with post-mortem analyses shown in Fig. 6.

Lastly, a fragmentation analysis is carried out in the vicinity of a volume of $1 \mathrm{~mm}^{3}$ located $13 \mathrm{~mm}$ ahead of the impact center. Table 2 shows the relevant fragmentation parameters computed for the maximum tensile strain rate $\dot{\epsilon}_{\text {max }}$ for the two impact velocities and for the two materials. In all cases, one has $\dot{\epsilon}_{\max }>\dot{\epsilon}_{t}$ so that a multiple fragmentation regime is observed experimentally and numerically. The cracking density at saturation $\lambda_{\mathrm{b}}(+\infty)$ in the porous $\mathrm{R}-\mathrm{SiC}$ is significantly greater than that of the infiltrated R-SiC. Moreover, $\lambda_{\mathrm{b}}(+\infty)$ is similar for a porous R-SiC impacted at $100 \mathrm{~m} / \mathrm{s}$ and an infiltrated $\mathrm{R}-\mathrm{SiC}$ impacted at $200 \mathrm{~m} / \mathrm{s}$. This result is consistent with the post-mortem observations of Section 3 and confirms the beneficial effect of aluminum infiltration on fragmentation.

\section{Summary}

A new SiC ceramic infiltrated by aluminum has been studied herein. In terms of density and Young's modulus, the values are less than those observed for denser SiC materials (such as $\mathrm{SiC}-100$ and SiC-B grades). Even lower values are found for the raw R-SiC material. Low average failure stresses are obtained when the two R-SiC materials are tested under quasi-static loading condition. Consequently, when dealing with quasi-static loadings, the two 
materials studied herein are weaker than denser monolithic $\mathrm{SiC}$ ceramics.

Edge-on-impact experiments were performed on the two R-SiC grades. When using a high-speed camera, no significant differences could be observed. A sarcophagus configuration was then used to allow for post-mortem analyses that are more precise in terms of observations of the cracking pattern. Macroscopic and microscopic analyses show that, when subjected to impact loadings leading to dynamic fragmentation, the R-SiC ceramic infiltrated with aluminum shows a significant reduction in cracking density when compared to the raw R-SiC material. Under this type of loading conditions, the aluminum skeleton provides sufficient cohesion for the cracks to be stopped.

The material parameters determined under quasi-static loading conditions are the only ones needed for the fragmentation model used herein. A damage model is then deduced. The finite element simulations using the damage and fragmentation models are able to predict the trends observed in the experiments for the two R-SiC grades. The numerical simulation of edge-on-impacts shows damage patterns in agreement with experimental observations, even though the second stage is slightly ahead of experimental observations. The cracking density and the size of the damage zone are identical for porous R$\mathrm{SiC}$ impacted at $100 \mathrm{~m} / \mathrm{s}$ and infiltrated $\mathrm{R}-\mathrm{SiC}$ impacted at $200 \mathrm{~m} / \mathrm{s}$. The infiltration has a strong influence on the initiation of cracks and a lesser effect on their propagation as it was assumed in the simulations. This is however going to be different when the residual strength will be assessed. This work is still in progress. 


\section{Acknowledgments}

This work was funded by DGA and is a collaboration within the network 'Pôle Francilien de Dynamique.'

\section{References}

[1] P. C. den Reijer, Impact on Ceramic Faced Armor, (PhD thesis, Delft Technical University, 1991).

[2] Internal data, (CTA, Arcueil (France), 2002).

[3] P. Riou, Contribution à l'étude de l'endommagement du carbure de silicium lors d'un impact de basse énergie : application aux blindages, $(\mathrm{PhD}$ thesis, École Nationale Supérieure des Mines de Paris, 1996).

[4] U. Hornemann, J. F. Kalthoff, H. Rothenhäusler, H. Senf and S. Winkler, Experimental Investigation of Wave and Fracture Propagation in Glass - Slabs Loaded by Steel Cylinders at High Impact Velocities, (EMI report E 4/84, Weil am Rhein (Germany), 1984).

[5] S. Winkler, H. Senf and H. Rothenhäusler, Wave and Fracture Phenomena in Impacted Ceramics, (EMI report V 5/89, Weil am Rhein (Germany), 1989).

[6] E. Strassburger and H. Senf, Experimental Investigations of Wave and Fracture Phenomena in Impacted Ceramics., (EMI report 3/94, Weil am Rhein (Germany), 1994).

[7] P. Riou, C. Denoual and C. E. Cottenot, Visualization of the Damage Evolution in Impacted Silicon Carbide Ceramics, Int. J. Impact Eng. 21 [4] (1998) 225235. 
[8] C. Denoual, C. E. Cottenot and F. Hild, On the Identification of Damage during Impact of a Ceramic by a Hard Projectile, Proc. 16th International Conference on BALLISTICS, (APDS, Arlington, VA (USA), 1996), 541-550.

[9] C. Denoual, C. E. Cottenot and F. Hild, Analysis of the Degradation Mechanisms in an Impacted Ceramic, in: S. C. Schmidt, D. P. Dandekar and J. W. Forbes, eds., Proc. Shock Compression of Condensed Matter, (AIP Press, New York (USA), 1998), 427-430.

[10] C. Denoual and F. Hild, Dynamic Fragmentation of Brittle Solids: A Multi-Scale Model, Eur. J. Mech. A/Solids 21 [1] (2002) 105-120.

[11] P.-F. Louvigné and P. Schulz, MMC for Armour Application : New Concept, Proc. of ICCE8 conference, Tenerife, Canary Islands, Spain (2001), 2p.

[12] E. Strassburger, B. Lexow, H. Ashuach, Y. Yeshurun, S. Bar-Ziv, Y. Hachamo and H. Gedon, Impact on Ceramic-Metal-Composites - Ballistic Resistance and Fracure Behavior, Proc. of $20^{\text {th }}$ Symposium on Ballistics, Orlando, FL (USA), (2002), 8p.

[13] P.-F. Louvigné, F. Feuchtenschlager, J. Reiter, G. Rettenbacher and P. Schulz, Blindage composite multicouche, PCT patent, PCT/FR02/024767 (2002).

[14] L. Tran, Etude de la fragmentation générée dans les céramiques $R$-SiC au cours d'essais d'impact sur la tranche, (MSc dissertation, University Paris 6, 2002).

[15] H. Kolsky, Stress Waves in Solids, (Dover Publications, New York (USA), 1963)

[16] W. Weibull, A Statistical Theory of the Strength of Materials, (Roy. Swed. Inst. Eng. Res., 151, 1939).

[17] W. Weibull, A Statistical Distribution Function of Wide Applicability, ASME J. Appl. Mech. 18 [3] (1951) 293-297.

[18] D. G. S. Davies, The Statistical Approach to Engineering Design in Ceramics, Proc. Brit. Ceram. Soc. 22 (1973) 429-452. 
[19] P. Forquin, C. Denoual, C. E. Cottenot, L. Rota and F. Hild, Experimental Approach and Modeling of the Compressive Behaviour of Two SiC Grades, $J$. Physique IV 10 (2000) Pr9-735-740.

[20] N. F. Mott, Fragmentation of Shell Cases, Proc. Roy. Soc. London A189 (1947) 300-308.

[21] D. E. Grady and M. E. Kipp, Geometric Statistics and Dynamic Fragmentation, J. Appl. Phys. 58 [3] (1985) 1210-1222.

[22] N. Kusano, T. Aoyagi, J. Aizawa, H. Ueno, H. Morikawa and N. Kobayashi, Impulsive Local Damage Analysis of Concrete Structure by the Distinct Finite Element Method, Nuclear Eng. Design 138 (1992) 105-110.

[23] G. T. Camacho and M. Ortiz, Computational Modelling of Impact Damage in Brittle Materials, Int. J. Solids Struct. 33 [20-22] (1996) 2899-2938.

[24] S. Mastilovic and D. Krajcinovic, High-Velocity Expansion of a Cavity within a Brittle Material, J. Mech. Phys. Solids 47 (1999) 577-600.

[25] H. D. Espinosa, P. D. Zavattieri and S. K. Dwivedi, A Finite Deformation Continuum/Discrete Model for the Description of Fragmentation and Damage in Brittle Materials, J. Mech. Phys. Solids 46 (1998) 1909-1942.

[26] D. E. Grady and M. E. Kipp, Continuum Modeling of Explosive Fracture in Oil Shale, Int. J. Rock Min. Sci. \&6 Geomech. Abstr. 17 (1980) 147-157.

[27] L. G. Margolin, Elasticity Moduli of a Cracked Body, Int. J. Fract. 22 (1983) $65-79$.

[28] A. M. Rajendran, Modeling the Impact Behavior of AD85 Ceramic under Multiaxial Loading, Int. J. Impact Eng. 15 [6] (1994) 749-768.

[29] C. Denoual and F. Hild, A Damage Model for the Dynamic Fragmentation of Brittle Solids, Comp. Meth. Appl. Mech. Eng. 183 (2000) 247-258. 
[30] D. A. Shockey, D. R. Curran, L. Seaman, J. T. Rosenberg and C. F. Petersen, Fragmentation of Rocks under Dynamic Loads, Int. J. Rock Mech. Min. Sci. 11 (1974) 303-317.

[31] R. Gulino and S. L. Phoenix, Weibull Strength Statistics for Graphite Fibres Measured from the Break Progression in a Model Graphite/Glass/Epoxy Microcomposite, J. Mater. Sci. 26 [11] (1991) 3107-3118.

[32] D. Jeulin, Modèles morphologiques de structures aléatoires et changement d'échelle, (thèse d'État, Université de Caen, 1991).

[33] C. Denoual and P. Riou, Comportement à l'impact de céramiques techniques pour blindages légers, (rapport CREA 95 R 005, Arcueil (France), 1995).

[34] L. B. Freund, Crack Propagation in an Elastic Solid Subjected to General Loading - Constant Rate of Extension, J. Mech. Phys. Solids 20 (1972) 129-140.

[35] C. Denoual, G. Barbier and F. Hild, A Probabilistic Approach for Fragmentation of Ceramics under Impact Loading, C. R. Acad. Sci. Paris $\mathbf{3 2 5}$ [Série IIb] (1997) 685-691.

[36] J. Lemaitre, A Course on Damage Mechanics, (Springer Verlag, Berlin (Germany), 1992).

[37] Pamshock, User's Manual, ESI (1996).

[38] K. Cho, N. Katz and I. Bar-On, Strength and Fracture Toughness of Hot Pressed SiC Materials, Ceram. Sci. and Eng. Proc. 16 (1995).

[39] R. Palika, Private communication, (1995). 


\section{List of Tables}

1 Mechanical properties of various materials.

2 Fragmentation data $13 \mathrm{~mm}$ ahead of the impact point for a volume of $1 \mathrm{~mm}^{3}$. 
Table 1

Mechanical properties of various materials.

\begin{tabular}{|c|c|c|c|c|c|}
\hline Material & $\mathrm{SiC}-100^{\sharp}$ & $\mathrm{SiC}-\mathrm{B}^{b}$ & $\mathrm{R}-\mathrm{SiC}$ & $\mathrm{R}-\mathrm{SiC}-\mathrm{Al}$ & steel $^{\natural}$ \\
\hline Young's modulus $E$ (GPa) & 410 & 455 & 260 & 317 & 210 \\
\hline Poisson's ratio $\nu$ & 0.15 & 0.16 & 0.16 & 0.17 & 0.3 \\
\hline Density & 3.15 & 3.20 & 2.64 & 2.99 & 7.8 \\
\hline Porosity & $1.8 \%$ & 0 & $17 \%$ & $2.5 \%$ & 0 \\
\hline Yield stress $\sigma_{\mathrm{y}}(\mathrm{MPa})$ & - & - & - & - & 1300 \\
\hline Weibull modulus $m$ & 9.6 & 27 & 26.5 & 24 & - \\
\hline Mean strength $\sigma_{\mathrm{w}}(\mathrm{MPa})$ & 360 & 560 & 100 & 200 & - \\
\hline Effective volume $\left(\mathrm{mm}^{3}\right)$ & 1.25 & 1.25 & 1.25 & 1.25 & - \\
\hline Number of samples & 65 & 30 & 19 & 12 & - \\
\hline Type of test & $\begin{array}{l}\text { 3-point } \\
\text { flexure }\end{array}$ & $\begin{array}{l}\text { 4-point } \\
\text { flexure }\end{array}$ & $\begin{array}{l}3 \text {-point } \\
\text { flexure }\end{array}$ & $\begin{array}{l}\text { 3-point } \\
\text { flexure }\end{array}$ & - \\
\hline
\end{tabular}

$\sharp$ : after Ref. [33]

b: after Refs. [38,39]

ต: AFNOR 35NCD16 steel heated to $875^{\circ} \mathrm{C}$, quenched and annealed at $550^{\circ} \mathrm{C}$ for

$2 \mathrm{~h}$ (chemical composition in wt\%: $\mathrm{C}=0.38, \mathrm{Si}=0.30, \mathrm{Mn}=0.60, \mathrm{Cr}=1.50$, $\mathrm{Mo}=0.40, \mathrm{Ni}=4.30, \mathrm{Fe}=$ balance $)$

Forquin et al. 
Table 2

Fragmentation data $13 \mathrm{~mm}$ ahead of the impact point for a volume of $1 \mathrm{~mm}^{3}$.

\begin{tabular}{|l|cc|cc|}
\hline Material & R-SiC & & \multicolumn{2}{|l|}{ R-SiC-Al } \\
\hline Impact velocity $(\mathrm{m} / \mathrm{s})$ & 100 & 200 & 100 & 200 \\
\hline$\sigma_{\mathrm{w}}(\mathrm{MPa})$ & 100 & 100 & 200 & 200 \\
$\dot{\epsilon}_{t}\left(\mathrm{~s}^{-1}\right)$ & 530 & 530 & 950 & 950 \\
\hline$\dot{\epsilon}_{\max }\left(\mathrm{s}^{-1}\right)$ & 3900 & 5660 & 3880 & 7310 \\
$\Sigma_{\max }(\mathrm{MPa})$ & 126 & 131 & 238 & 255 \\
$\lambda_{\mathrm{b}}(+\infty)\left(\mathrm{mm}^{-3}\right)$ & 6059 & 16513 & 1058 & 5722 \\
$t_{c}(\mu \mathrm{s})$ & & & & \\
\hline
\end{tabular}

Forquin et al. 


\section{List of Figures}

1 Limit velocity of penetration vs. mass per unit surface of armor for different materials (after Ref. [2]).

2 a-Schematic of a normal impact on a bilayered system. Post-mortem observation of a SiC-100 ceramic / armor steel backing impacted by a steel projectile (AFNOR 100C6, AISI $52100)$ at $250 \mathrm{~m} / \mathrm{s}$.

b-Edge-on-impact of a bilayered system (left) and a ceramic (right) $2.9 \mu$ s after impact by a steel projectile (AFNOR 100C6, AISI 52 100) at $250 \mathrm{~m} / \mathrm{s}$. c-Schematic of a sarcophagus configuration and post-mortem observation of a $\mathrm{SiC}-100$ ceramic impacted by a steel projectile (AFNOR 100C6, AISI 52100 ) at $330 \mathrm{~m} / \mathrm{s}$.

3 View of a multilayered armor made of R-SiC-Al ceramics impacted by an AP $7.62 \mathrm{~mm}$ bullet. No perforation can be observed and the fragmentation process is confined around the impact zone (see zooms of three different zones).

5 Comparison of damage patterns for an R-SiC (a) and R-SiC-Al

(b) ceramic impacted by a steel projectile travelling at 202 $\mathrm{m} / \mathrm{s}$. 
6 Post-mortem observations and zoom around a central zone located $13 \mathrm{~mm}$ from the impact point:

R-SiC impacted at $100 \mathrm{~m} / \mathrm{s}$ (a) and $200 \mathrm{~m} / \mathrm{s}$ (b), R-SiC-Al impacted at $200 \mathrm{~m} / \mathrm{s}(\mathrm{c})$.

7 Mesh of one quarter of a ceramic tile and a striker.

8 Change of the cracking density with time: $\mathrm{t}=2 \mu \mathrm{s}(\mathrm{a}), \mathrm{t}=$ $3 \mu \mathrm{s}(\mathrm{b}), \mathrm{t}=4 \mu \mathrm{s}(\mathrm{c})$ after impact for R-SiC impacted at 100 $\mathrm{m} / \mathrm{s}$ (left) and $200 \mathrm{~m} / \mathrm{s}$ (middle), R-SiC-Al impacted at 200 $\mathrm{m} / \mathrm{s}$ (right). 


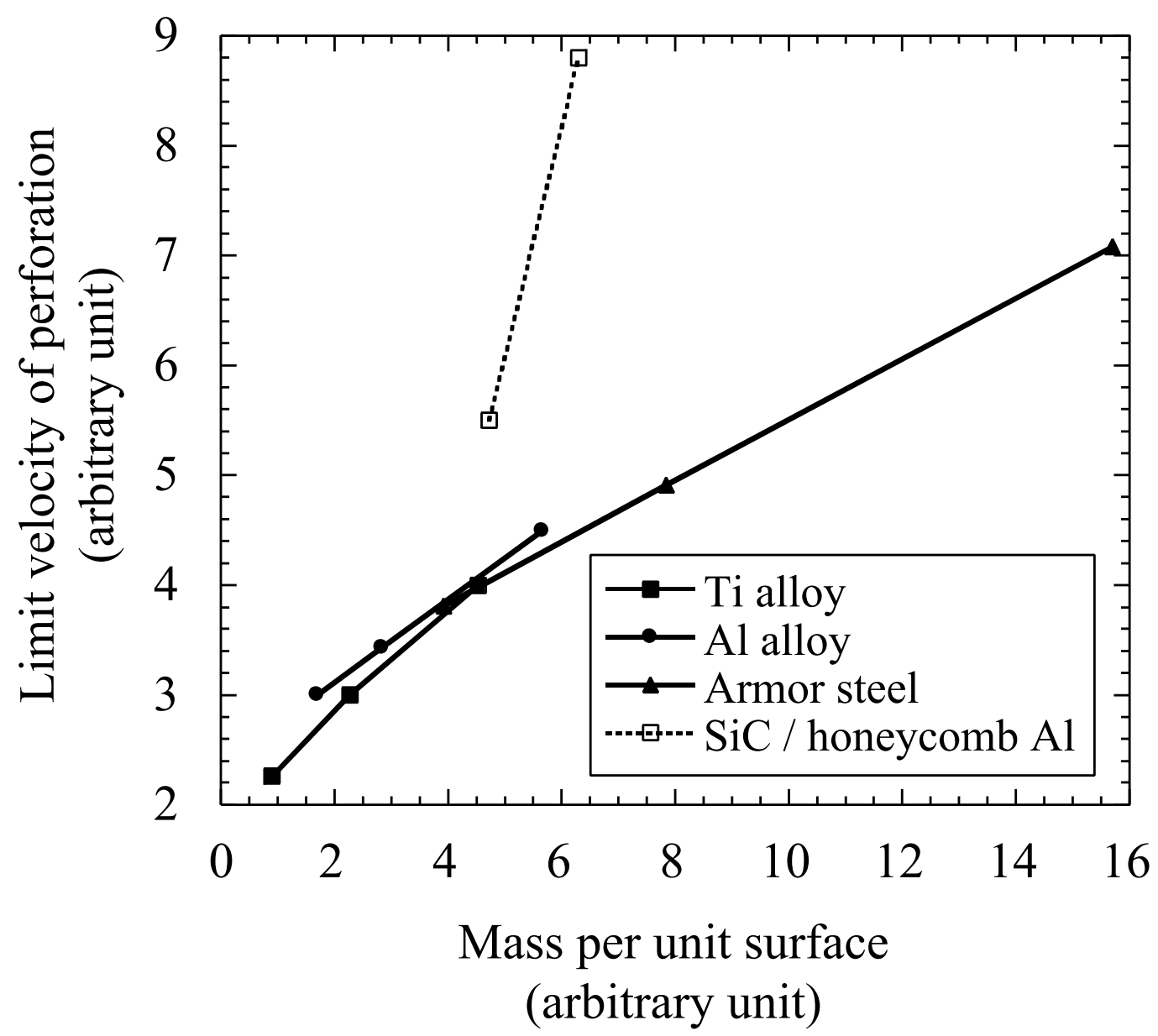

Fig. 1. Limit velocity of penetration vs. mass per unit surface of armor for different materials (after Ref. [2]).

Forquin et al. 


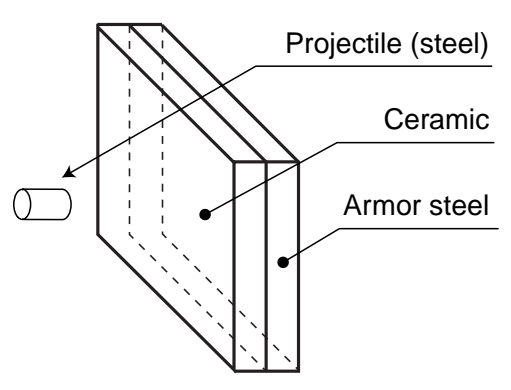

$-a-$
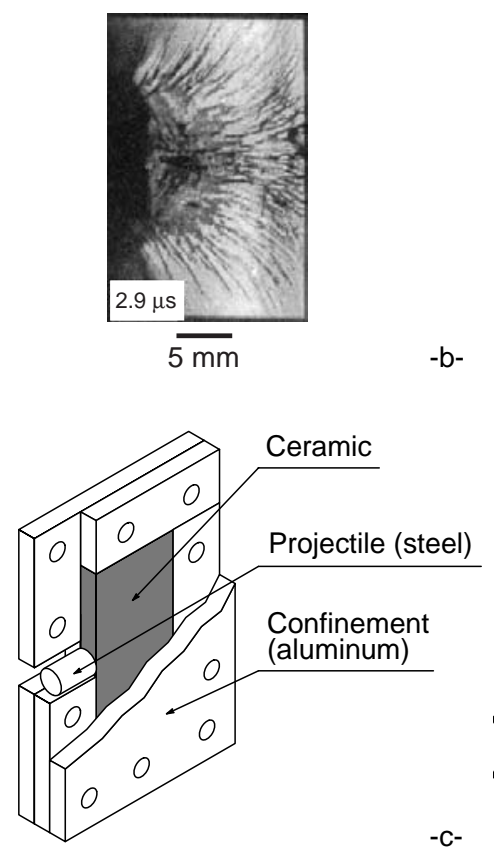
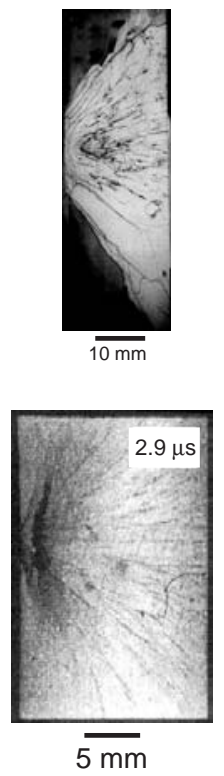

$-b-$

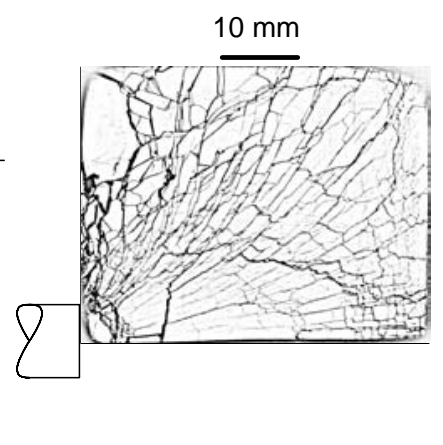

Fig. 2. a-Schematic of a normal impact on a bilayered system. Post-mortem observation of a SiC-100 ceramic / armor steel backing impacted by a steel projectile (AFNOR 100C6, AISI 52100 ) at $250 \mathrm{~m} / \mathrm{s}$.

b-Edge-on-impact of a bilayered system (left) and a ceramic (right) $2.9 \mu$ s after impact by a steel projectile (AFNOR 100C6, AISI 52 100) at $250 \mathrm{~m} / \mathrm{s}$.

c-Schematic of a sarcophagus configuration and post-mortem observation of a SiC-100 ceramic impacted by a steel projectile (AFNOR 100C6, AISI 52 100) at $330 \mathrm{~m} / \mathrm{s}$.

Forquin et al. 


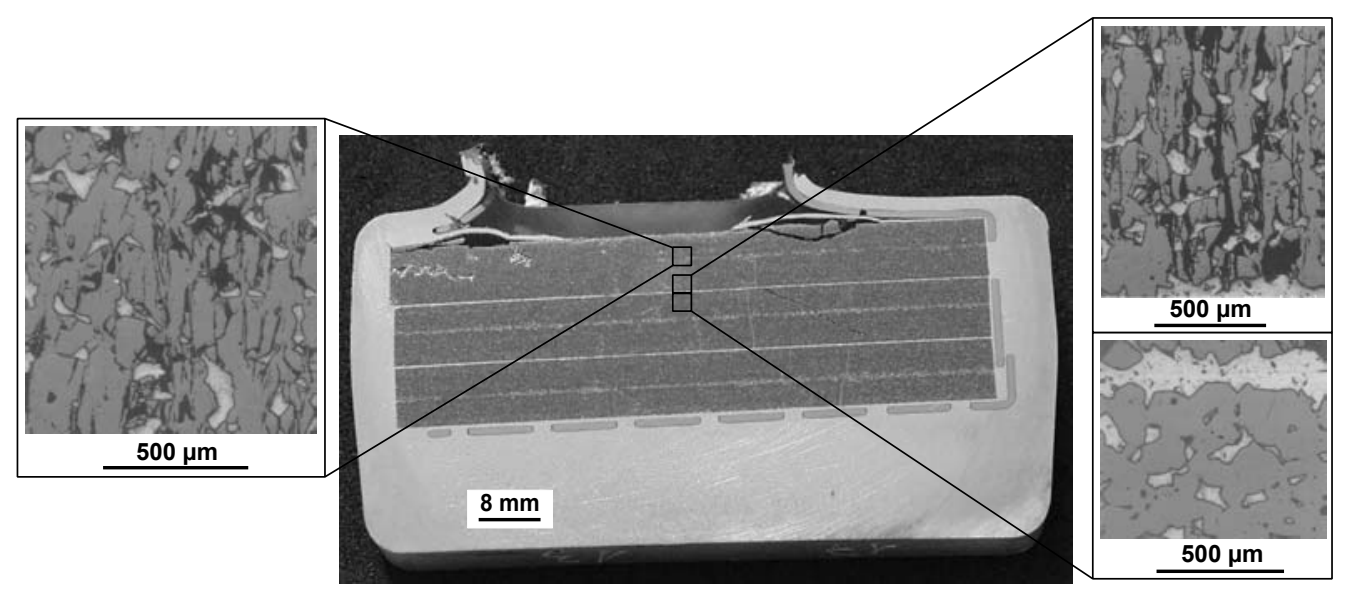

Fig. 3. View of a multilayered armor made of R-SiC-Al ceramics impacted by an AP $7.62 \mathrm{~mm}$ bullet. No perforation can be observed and the fragmentation process is confined around the impact zone (see zooms of three different zones).

Forquin et al. 


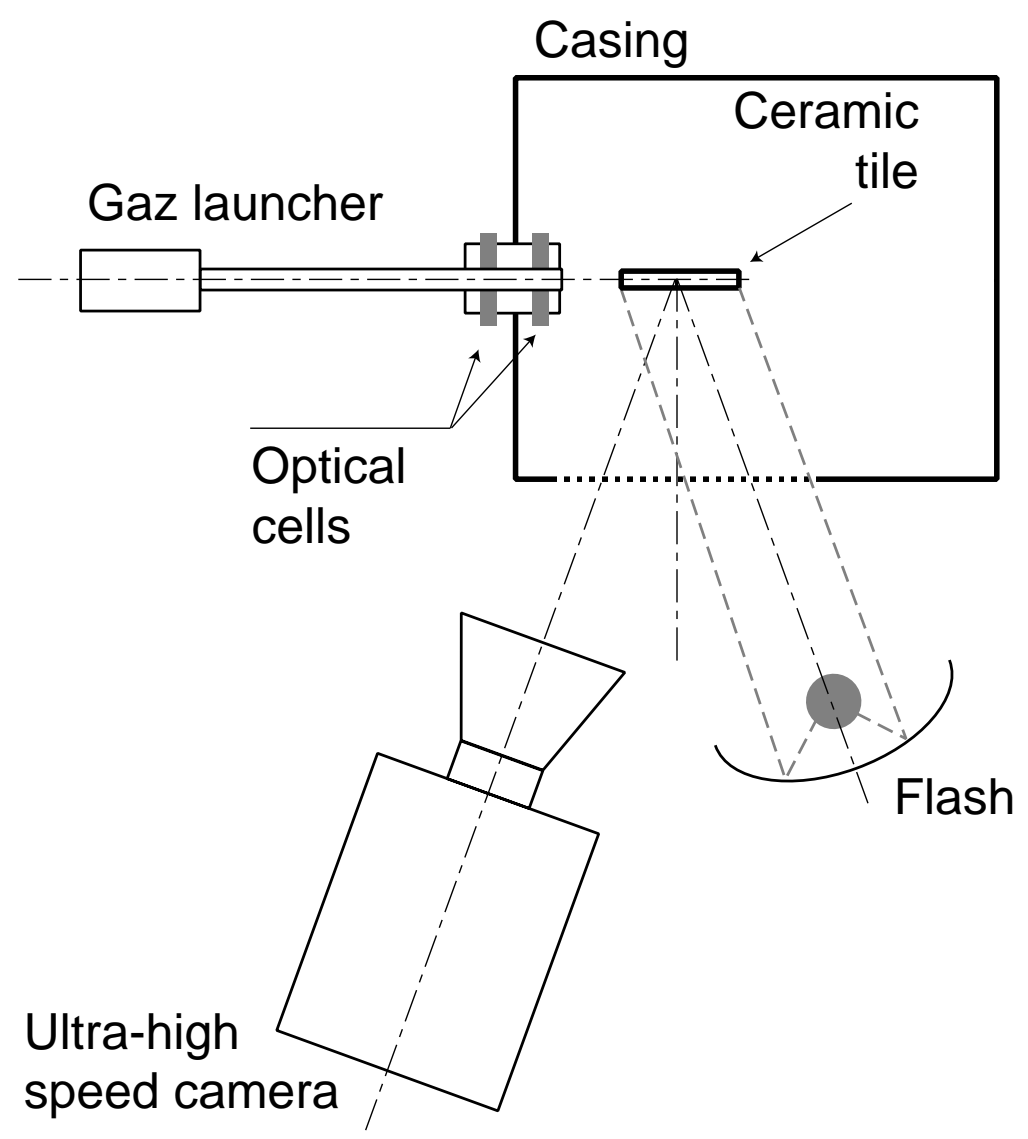

Fig. 4. Experimental configuration for EOI experiments.

Forquin et al. 


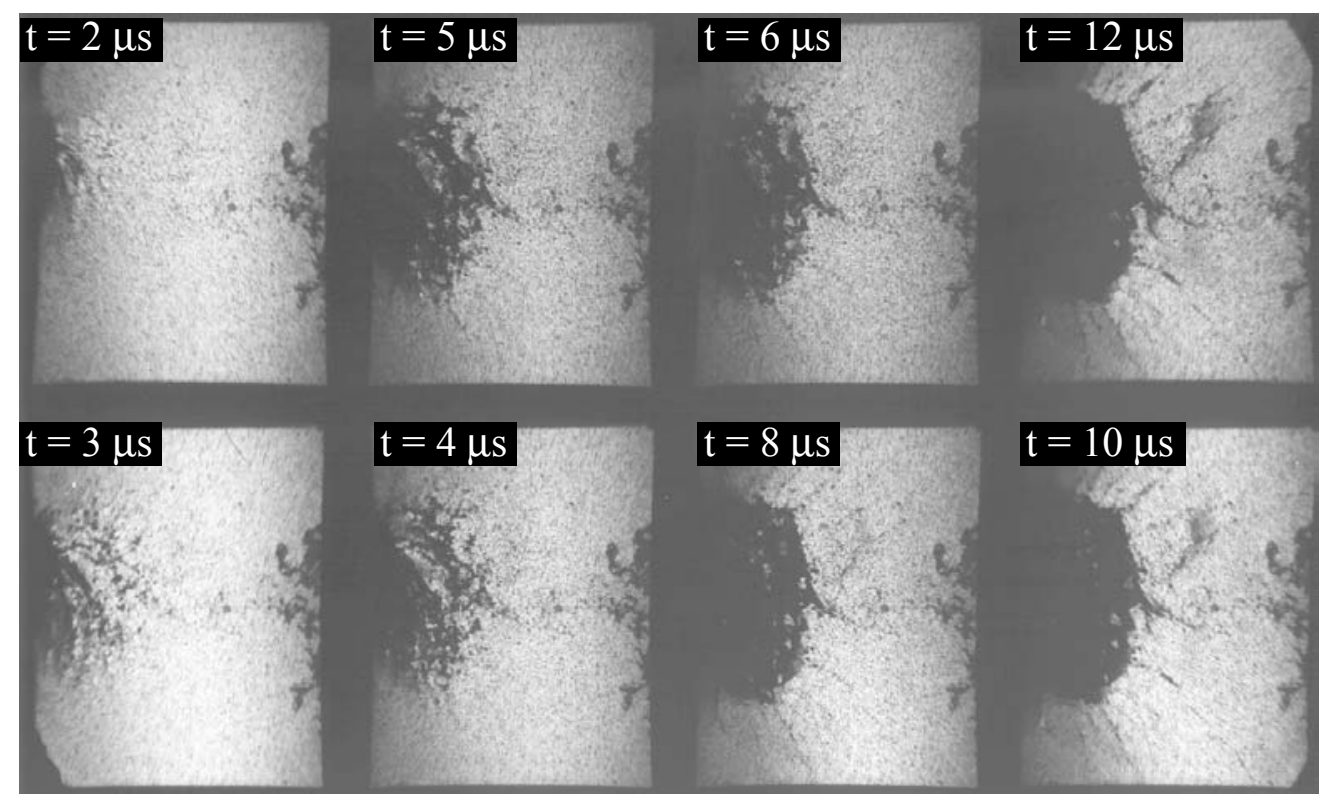

$-a-$

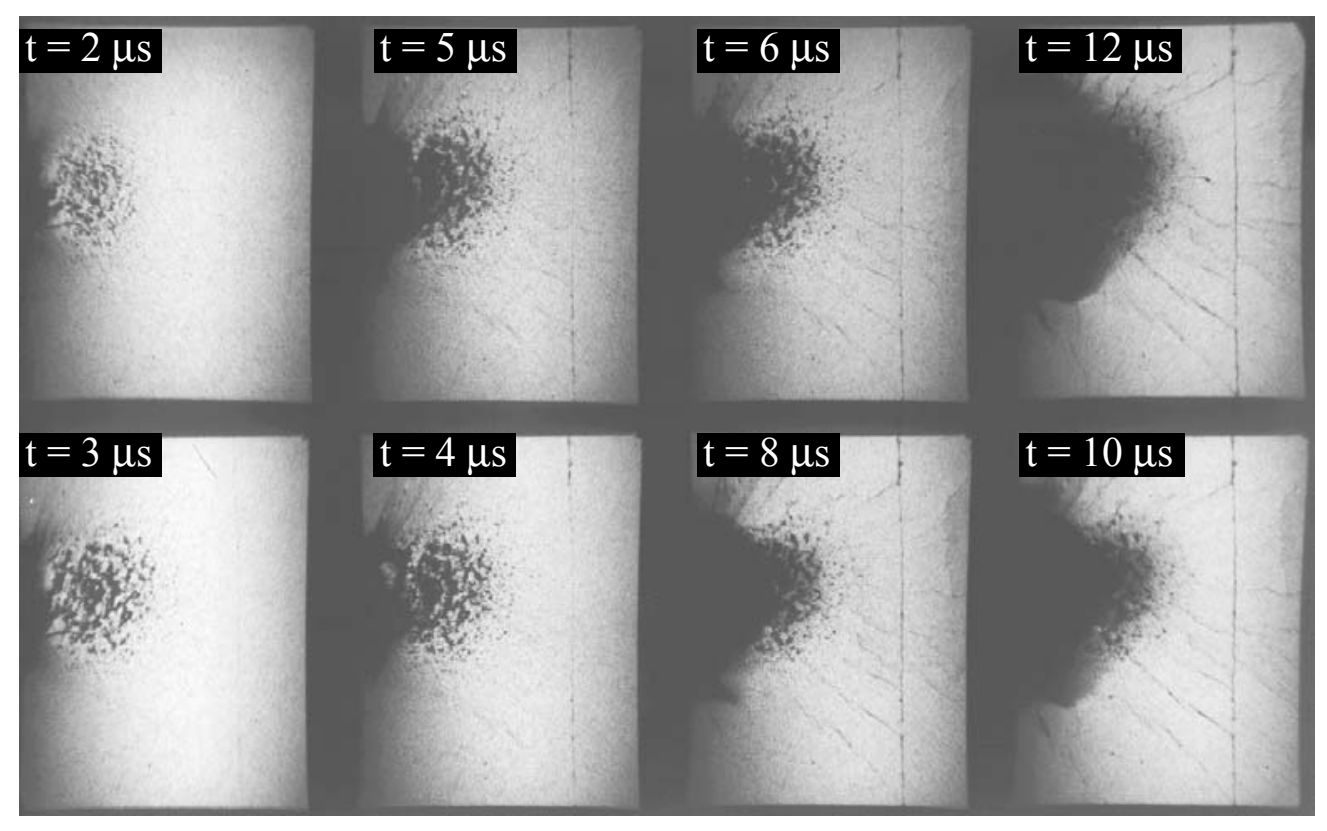

$-b-$

Fig. 5. Comparison of damage patterns for an R-SiC (a) and R-SiC-Al (b) ceramic impacted by a steel projectile travelling at $202 \mathrm{~m} / \mathrm{s}$.

Forquin et al. 


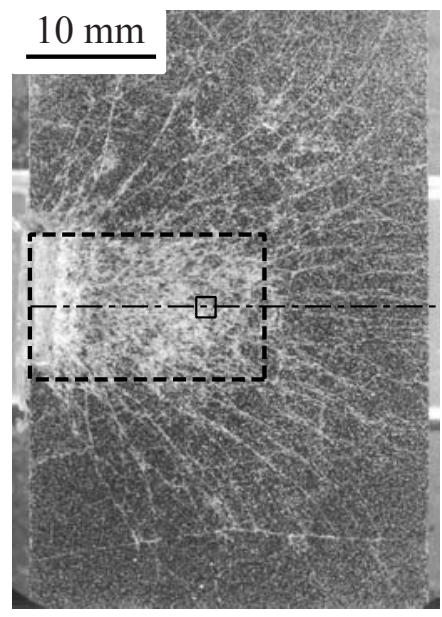

$-a-$

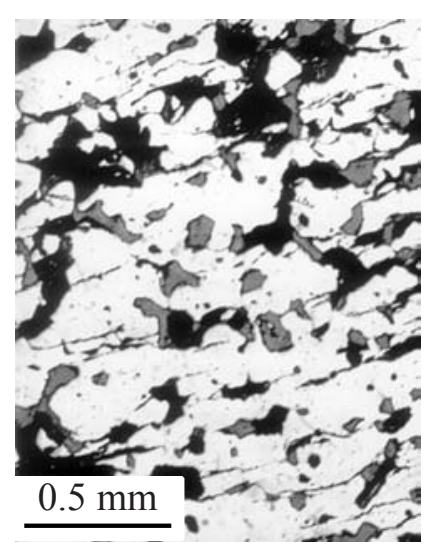

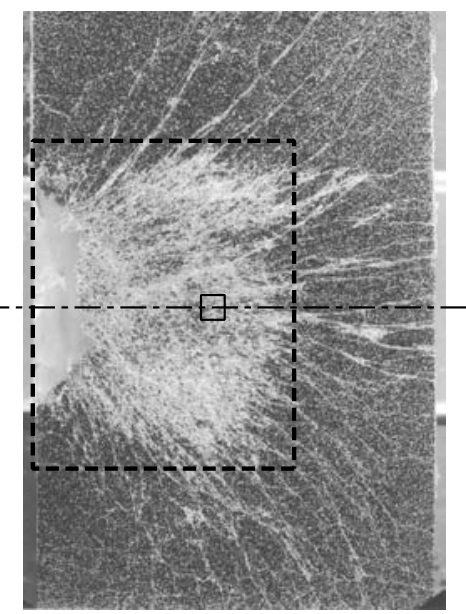

$-b-$

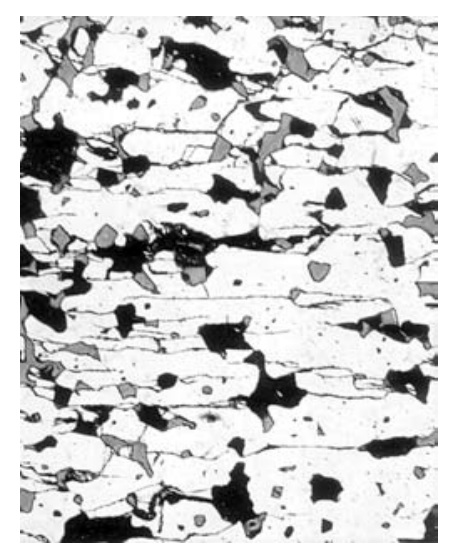

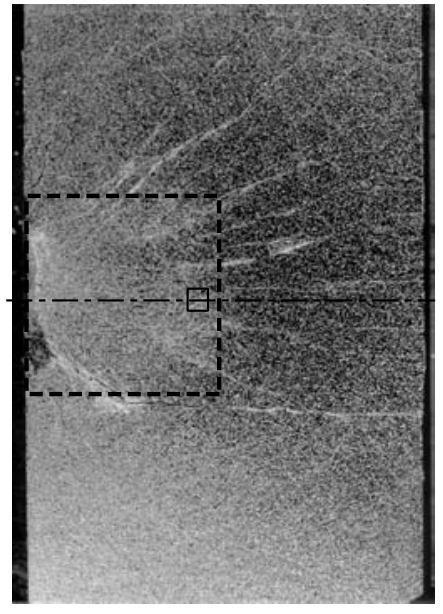

$-\mathrm{c}-$

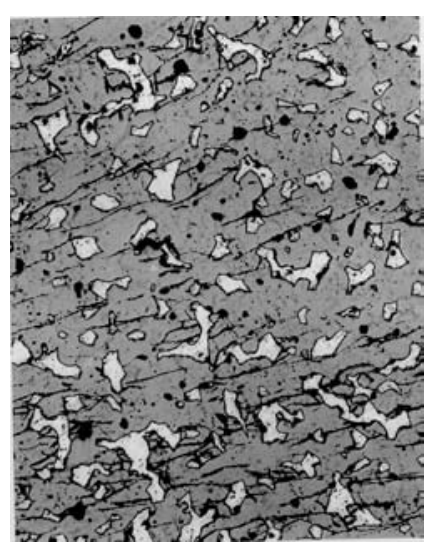

Fig. 6. Post-mortem observations and zoom around a central zone located $13 \mathrm{~mm}$ from the impact point:

R-SiC impacted at $100 \mathrm{~m} / \mathrm{s}$ (a) and $200 \mathrm{~m} / \mathrm{s} \mathrm{(b),} \mathrm{R-SiC-Al} \mathrm{impacted} \mathrm{at} 200 \mathrm{~m} / \mathrm{s}$ (c).

Forquin et al. 


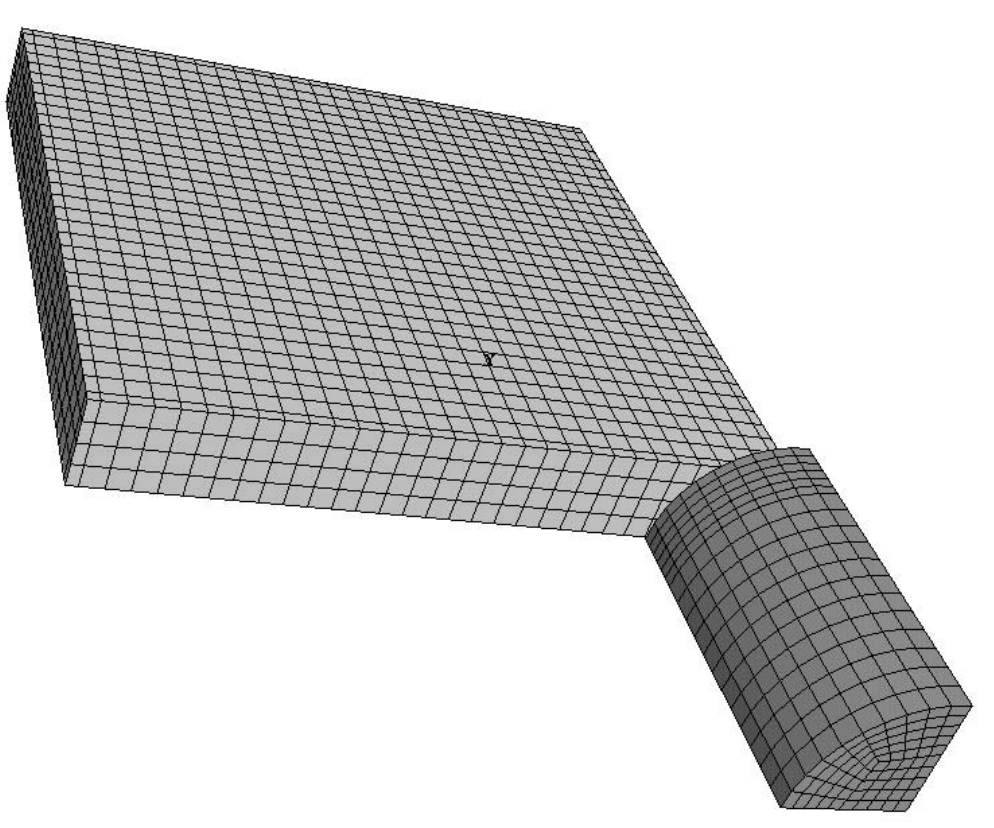

Fig. 7. Mesh of one quarter of a ceramic tile and a striker.

Forquin et al. 

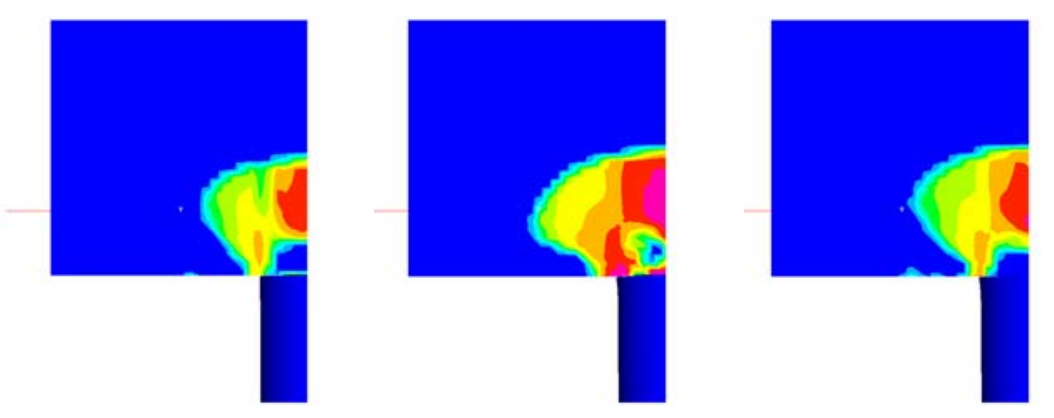

-a-
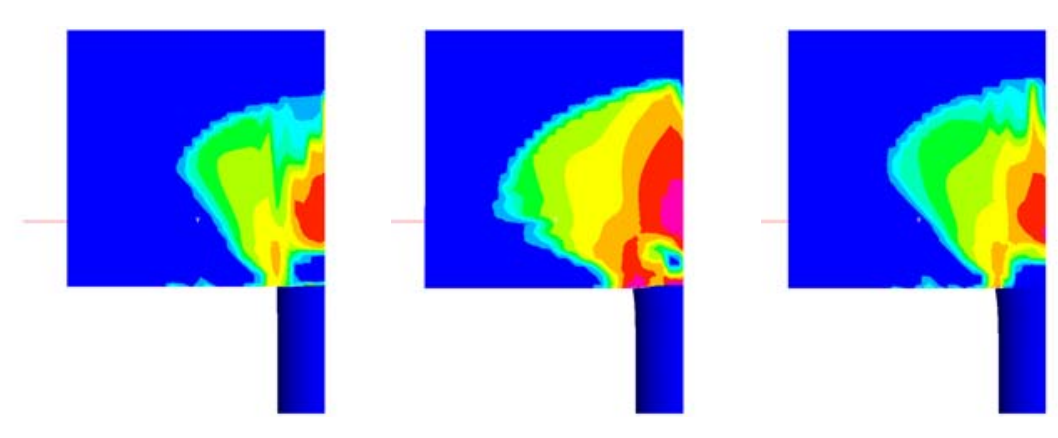

$-b-$
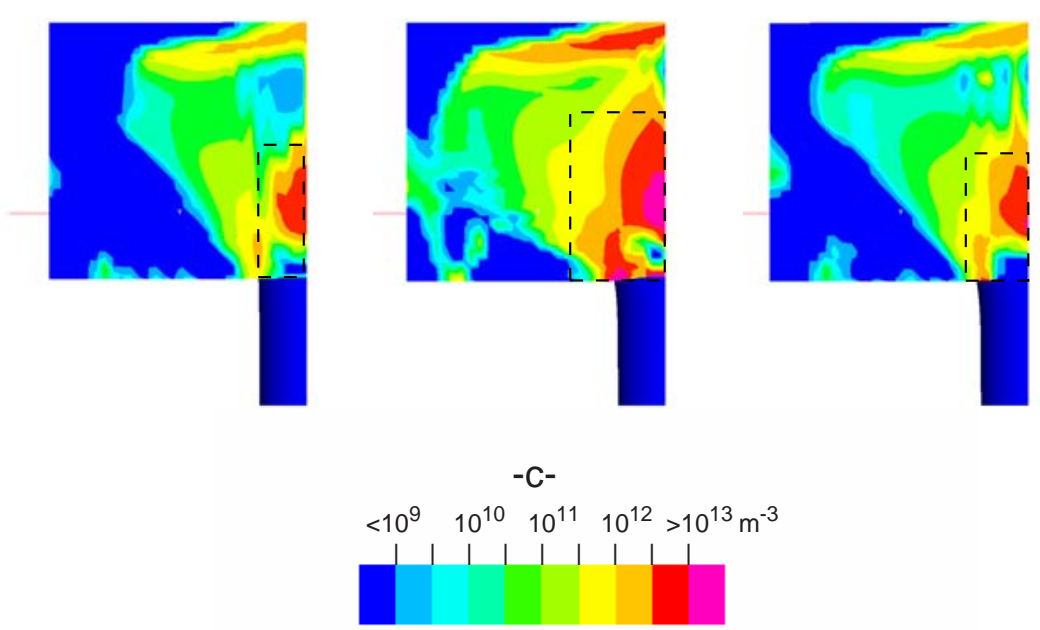

Fig. 8. Change of the cracking density with time: $\mathrm{t}=2 \mu \mathrm{s}(\mathrm{a}), \mathrm{t}=3 \mu \mathrm{s}(\mathrm{b}), \mathrm{t}=$ $4 \mu \mathrm{s}$ (c) after impact for R-SiC impacted at $100 \mathrm{~m} / \mathrm{s}$ (left) and $200 \mathrm{~m} / \mathrm{s}$ (middle), R-SiC-Al impacted at $200 \mathrm{~m} / \mathrm{s}$ (right).

Forquin et al. 